\title{
A Case Analysis of Lexical Features in English Broadsheets and Tabloids
}

\author{
Yingxia $\mathrm{Li}^{1}$, Dongyu Zhang ${ }^{1} \&$ Wanyi, $\mathrm{Du}^{1}$ \\ ${ }^{1}$ School of Software, Dalian University of Technology, Dalian, China \\ Correspondence: Yingxia, Li, School of Software, Dalian University of Technology, Teaching Building A, NO. \\ 321, Tuqiang Street, Development Area of Economy and Technology, Dalian, China. Tel: 86-186-9860-1305. \\ E-mail: amylyx@sina.com
}

Received: May 20, 2014 Accepted: June 29, 2014 Online Published: July 30, 2014

doi: 10.5539/ijel.v4n4p115 URL: http://dx.doi.org/10.5539/ijel.v4n4p115

\begin{abstract}
This paper investigates lexical features in two different styles of English newspapers-broadsheets (The New York Times, and The Times), and tabloids (New York Post and The Sun). The comparison and contrast are done in five lexical aspects: the use of compound words, fuzzy words, numbers, proper nouns and vivid words. Statistics show that differences do exist between broadsheets and tabloids. Analysis is done to reveal the possible causes that lead to the difference and provides evidence that lexical features are essential to set the tone of newspaper writing.
\end{abstract}

Keywords: broadsheets, tabloids, lexical features

\section{Introduction}

Distinctive differences exist between the styles of quality newspapers and popular newspapers, which are identified as broadsheets and tabloids in this paper. One way to probe into the differences between the two is to study the wording, which subtly reflects the perspectives and stances of writers of newspaper stories. Understanding how words may function in the tone of a piece of writing and reflect the writer's attitude poses a great challenge to language learners.

\subsection{Newspaper Categories: Broadsheets and Tabloids}

Newspapers can be classified into different categories based on different criteria: daily newspapers and weekly newspapers according to the frequency of publication; national newspapers and local newspapers according to the place of publication; and broadsheets and tabloids according to the content and styles.

Broadsheets focus mainly on hard news, which "include stories of a timely nature about events or conflicts that have just happened or are about to happen, and they usually focus on solid facts" (Zeng, 2006). Tabloids, on the other hand, tend to focus on soft news, such as social news and entertainment. Broadsheets include The Times, Daily Telegraph, Guardian from UK, and The New York Times, The Washington Post, USA Today from the USA. Tabloids include Daily Mirror, Daily Mail, and The Sun from UK, and New York Post, The National Enquirer, and National Examiner from the USA.

Works that outline the schools and theories of stylistics and introduce the varieties include: Investigating English Style (David \& Derek, 1969), Papers in English stylistics (Wang, 1980); Introduction to English Stylistics (Wang \& Ding, 1985); A Survey of Stylistics (Qin, 1986); Varieties of English (Hou, 1988); Theoretical Stylistics (Hu, 2000), English in News Publications (Zhang, 2007), etc.

In his book Investigating English Style, David Crystal makes contrastive studies on broadsheets and tabloids at several stylistic levels, such as graphological level, grammatical level, syntactic level, and lexical level. He points out that "the language of newspaper reporting is evidently a very general label which should be used with great care" (Crystal \& Davy, 1969), because different newspapers would choose different reporting styles to cater for different audiences' interests, though they are reporting the same fact.

In English in Publication, Zhang Jian elaborates the nature of English news and some stylistic features of English news. He lists eleven lexical features of English news, including the use of brief language, borrowing words, nonce words, fuzzy words, and vivid words, etc. He proposes examples to exhibit functions of these 
lexical features in English news reporting.

\subsection{Analysis of Lexical Usages in Broadsheets and Tabloids}

Lexical choices in English news reports are made in the considerations of target readers, purposes, the subject matters, and linguistic competence of the writers. English newspapers have gradually formed its own lexical features to achieve the $\mathrm{ABC}$ principle (Accuracy, Brevity, \& Clarity).

Some words gain new meanings because they are frequently used in particular types of news reports, and they gradually become idiomatic expressions in news reporting. These words are usually short and striking. For example: accord (give), allege (declare), bid (attempt), clash (disagreement), cut (reduction), deal (business), move (plan), shun (keep away from), stance (stand), voice (to express), etc.

Furthermore, nonce words, which are also called journalistic neologism, represent one of the prominent features of English newspapers. Nonce words refer to words coined temporarily as required, so as to make up the shortage of necessary expressions and convey their intentions explicitly. They are used often to meet the requests of expressiveness and originality. For example: hijack (illegally take control of something by force), unisex (things can be used by both men and women), drop-out (out of date), atobomb (atom bomb), Eurasia (Europe Asia), teleceiver (television receiver), digicom (digital computer), fruice (fruit juice), etc..

Using short words is also an effective approach to make a news report brief and clear. Short words can be classified into three categories: clipping, such as mod (modern), pop (popular), ad (advertisement), celeb (celebrity), flu (influenza); blending, such as brunch (breakfast and lunch), infoport (information airport), motel (motor hotel); and acronym, such as NATO (North Atlantic Treaty Organization), APEC (Asia-Pacific Economic Co-operation), IMF (International Monetary Fund), OPEC (Organization of Petroleum Exporting Countries), etc..

Other ways of managing words include: novelty, literary quotation, metonymy, slang, figurative words and adjectival formations.

This paper will analyze four news reports about the same subject as samples, two broadsheets - The New York Times and The Times, and two tabloids-New York Post and The Sun. Comparisons and contrasts are done in five aspects based on previous studies and data collection: use of compound words, fuzzy words, numbers, proper nouns and vivid words. The assumption here is that differences do exist at lexical level between broadsheets and tabloids; lexical variations influence newspaper styles and are responsible for the formation of the styles.

\section{Methods}

\subsection{Principle of Data Collection}

The newspapers that have been selected for the concern in this paper are published on March 13, 2009 in the United States and Great Britain: two broadsheets-The New York Times (USA) and The Times (UK); and two tabloids-New York Post (USA) and The Sun (UK). The four samples selected from the newspapers above are reports about a same subject matter- Madoff pleas guilty in Ponzi scheme.

The New York Times and The Times are selected for their influence and large circulation in their own country. The New York Times is the first newspaper published in New York, and is also the first quality newspaper published in the United States. Its circulation reaches 1.1 million readers daily (1.7 million on Sundays). The Times is one of the most important broadsheets in Britain, and its circulation reaches 0.69 million per day. The consideration of selecting The Sun is that it has the highest circulation of any daily English-language newspaper in the world and the biggest circulation within the UK, with 3.12 million per day.

The headlines of selected samples are ( $\mathrm{B}$ for broadsheets and $\mathrm{T}$ for tabloids):

B1: Madoff Goes to Jail After Guilty Pleas to All Charges (from The New York Times)

B2: I knew it was criminal fraud and I'm sorry, says Bernard Madoff (from The Times)

T1: Madoff Pleads Guilty in \$65 Ponzi Scheme (from New York Post)

T2: Madoff to Jail (from The Sun)

\subsection{Contrast of Lexical Features}

Targeting at different audience groups, journalists of broadsheets and tabloids often select different styles of words to report one same fact, and gradually shaped distinctive lexical features between the two. The following parts will analyze the differences from five aspects: compound words, fuzzy words, numbers, proper nouns, and vivid words. The analysis also aims at demonstrating how writing styles are formed at lexical level, and enhance 
ESL learners' awareness of wording features in newspaper reading.

\subsubsection{Compound Words}

Combination of two or more roots is technically called compounding or composition. The new words that created by stringing words together are called compound words, or simply compounds. The productivity of compound words is limitless, because there is almost no limit on the kinds of combination, and words are the loosest elements and combine most freely. (Li, 2001)

Types of compound words are as productive as those of compounding. In English, all major categories of words are represented, which are nouns (such as poorhouse, rainbow, handbook), verbs (such as overturn, dryclean, outlive), adjectives (such as easygoing, taxfree, red-hot). Besides these major categories of words, there are compound prepositions (alongside), compound adverbs (moreover), compound pronouns (yourself); compound numbers (one-third), and other types of compound words.

The compound words used in the samples are basically the compound words of three major categories. For example:

Nouns: courtroom (B1), wrongdoing (B1), light-years (B1), hallway (B1), undercurrent (B1), cupboard (B2), downfall (B2), heavyweight (B2), talk-show (B2), courthouse (T1), bodyguard (T1), money-laundering (T2)

Verbs: handcuff (B1)

Adjectives: award-winning (B1), court-appointed (B1), walk-in (B2), grim-faced (T1), once-reserved (P1), low-level (P1), etc.

Contrasts of compound words in sample news reports will be shown by the following table.

Table 1. Number of compound words and the percentage compared in the sample reports

\begin{tabular}{lcccc}
\hline Samples & Q1 & Q2 & P1 & P2 \\
\hline Number of compound words & 16 & 10 & 9 & 1 \\
Number of total words & 1272 & 813 & 680 & 375 \\
Percentage of compound words & $1.26 \%$ & $1.23 \%$ & $1.32 \%$ & $0.26 \%$ \\
\hline
\end{tabular}

The function of using compound words is mainly to create more accuracy when reporting facts. More importantly, these words are also easily accepted by the audience. For example, "The feds said that the once-revered investment fund manager admitted to his sons last year that his firm was all a big lie-a Ponzi scheme that wiped out fortunes and trust funds" (B1). In this sentence, once-revered is a compound word which means being respected before. Here it vividly describes the state of Madoff after he was arrested, and precisely reflected the contrast of his situations before and after his arresting.

Statistics in Table 1 exhibit that English news reports in both broadsheets and tabloids employ compound words whenever necessary, most of which perform functions of nouns and attributives. The number of compound words used in the two broadsheets samples is relatively larger than that of tabloids, but the difference is not significant. However, it provides evidence that using compound words is one of the common features of English newspapers. They are, more often than not, coined impromptu by the writer to achieve special effect. For ESL learners, understanding the structure and patterns of compound words help them improve their reading comprehension as well as acquisition of English vocabulary.

\subsubsection{Fuzzy Words}

One of the principles of newspaper reporting is to achieve accuracy. However, sometimes it is not easy to identify clear boundaries between things or facts. When writers cannot depict a situation precisely as what it is, fuzzy words turn to be a wiser option, especially when to avoid possible controversy over some sensitive issues. A news report, therefore, become more reasonable, reliable, and acceptable to the public.

Zadeh (1965) proposed the concept of vagueness of language in his book Fuzzy Sets. He argued that if an expression lacks accurate boundary to its opposite, the expression is defined as "fuzzy language." Fuzzy language is ambiguous. Ambiguity is required in a newspaper report because it indicates more flexibility, and is a protective way to reduce risks in a newspaper report. In a way, using fuzzy expressions shows an attitude of the 
writer of respecting the fact and being objective.

The types of fuzzy words roughly fall into two categories: words without definite limit, such as recently, these days, and past years, etc.; and words without clear extent to which express relative meanings, such as high, short, blue, etc. Specifically, fuzzy words can be divided into at least three categories: abstract nouns (love, hatred, democracy, freedom, life, spirit, etc.), numerals (tens of, dozens of, hundreds of, or thousands of, etc.), and hedges with fuzzy meaning (about, approximately, probably, almost, to some extent, strictly speaking, generally speaking, basically, more or less, somewhat, etc.).

Fuzzy words represented in the four samples are mainly numerals, words describing time, some adjectives and hedges. For example:

Numeral: thousands of (B1), dozens of (B1), a handful of (B1), later (B1), some of (B2), the reams of (B2), a few of (T2), less than (B2), more than (T1), about (T1), etc.

Time: at times (B1), the early 1990s (B1), sometimes (B2), 1980s (B2), moments (T1), the years (T1), the past three months (T1), last year (T1), under 24-hour (B2), around 2002 (T2), etc.

Hedges: nearly (B1), shortly (B1), almost (B1), probably (B1), barely (B1), repeatedly (B1), likely (B2), approximately (B2), immediately (T1), etc.

Adjective: vast (B1), more light (B1), most famous (B2), incentive (B2), hollow (B2), etc.

Table 2. Number of fuzzy words and the percentage compared with total number of words in the sample reports

\begin{tabular}{lcccc}
\hline Samples & B1 & B2 & T1 & T2 \\
\hline Number of fuzzy words & 44 & 30 & 22 & 10 \\
Number of total words & 1272 & 813 & 680 & 375 \\
Percentage of fuzzy words & $3.46 \%$ & $3.69 \%$ & $3.24 \%$ & $2.67 \%$ \\
\hline
\end{tabular}

Table 2 shows that broadsheets use more fuzzy words than tabloids. In a way, it indicates that broadsheets tend to pick words more cautiously that tabloids. Fuzzy words obviously help writers perform an attitude of pursuing accuracy and reliability. For example: "Madoff, 70, appeared nervous as he came face to face with several dozen of his former clients in Manhattan Federal Court" (B2). In this sentence, "several dozen of" are fuzzy words which describe the large number of victims who came to the hearing and the importance of this case. The writer does not know the exact number of audience present at the hearing, so he/she uses a fuzzy expression to indicate he or she can be responsible for what is written in the report. For ESL learners, using fuzzy expressions might be a wise policy when things are uncertain and when potential risks need to be reduced.

\subsubsection{Numbers}

A news report should be concise enough for the readers to grasp main idea within the least amount of time; therefore, a way of dealing with numbers in news reports to achieve such purpose is "the rule of ten". Journalists usually spell out all numbers that are no more than ten while using Arabic numerals for any numbers over ten. However, there might be some exceptions. For instance, in the indication of date, Arabic numbers are generally employed although sometimes the number is less than ten, such as phrases like "Mar. 19", and "November 7" that suggest the exact date of an event. In most cases, however, English journalists observe the rule mentioned above.

In the samples, most of numbers are represented according to "the rule of ten" in both broadsheets and tabloids, while there are some exceptions which suggest exact numbers, such as " $\$ 1$ billion" $(\mathrm{B} 1, \mathrm{~B} 2, \mathrm{~T} 1)$ and " $\$ 7$ billion" $(\mathrm{T} 1, \mathrm{~T} 2)$.

From the aspect of using numbers, contrasts of sample news reports will be shown by the following table. 
Table 3. Numbers used in the samples and the percentage compared with total number of words in the sample reports

\begin{tabular}{lllll}
\hline Samples & $\mathrm{B} 1$ & $\mathrm{~B} 2$ & $\mathrm{~T} 1$ & $\mathrm{~T} 2$ \\
\hline Numbers in the samples & 20 & 15 & 20 & 14 \\
Number of total words & 1272 & 813 & 680 & 375 \\
Percentage of numbers & $1.57 \%$ & $1.84 \%$ & $2.94 \%$ & $3.73 \%$ \\
\hline
\end{tabular}

It is interesting to note that numerals are used in tabloids are significantly more than those in broadsheets. It is commonly acknowledged that number provides solid evidence for reporting events. Therefore, broadsheets presumably use more numbers to prove its authority. However, statistics in table 3 shows the opposite. Does that mean tabloids intend achieve more reliability than broadsheets?

When people read newspapers, they apply reading skills like skimming and scanning more than careful reading. Numbers certainly are more eye-catching than common words. Readers easily spot numbers and in tabloids, besides titles, numbers seem to offer the most valuable information than anything else. Broadsheets, on the other hand, focus more on the cause and effect, the development and progression, and the consequence and influence of one important event. Therefore, small wonder that the statistics are as what are shown in Table 3.

\subsubsection{Proper Nouns}

Nouns can be further divided into common nouns and proper nouns. Proper nouns (also called proper names) are nouns representing unique entities (such as USA, Earth or Jane). They distinguish from common nouns and describe a class of entities (such as a city, a planet or a person). Proper nouns are used to indicate a particular person, place, or thing without consideration of any descriptive meaning the word or phrase may have. Proper nouns have two distinctive features: one is that they will name a specific kind of items; the other is that they will begin with capital letters no matter where they occur in a sentence.

Proper nouns can be used in three types of forms: full names (such as White House, Wall Street, Fleet Street, etc.), abbreviations (such as phone, flu, bike, etc.), acronyms (such as $A P E C, I M F$, UK, etc.). The proper nouns occurred in the samples are mainly full names and acronyms. For example:

Full names: Bernard L. Madoff (B1, B2, T1, T2), Manhattan (B1, B2, T1, T2), Ponzi scheme (B1, B2, T1), Wall Street (B1, B2, T1, T2), Ruth (B1, B2, T1, T2), Peter (B1, B2, T1, T2), Mark (B1, B2, T1, T2), George Nierenberg (B1), Judge Denny Chin (B1, B2, T1, T2), Federal District Court (B1), Brooklyn (B1), Upper East Side (B1, B2, ), Armonk (B1), Los Angeles (B1), New Jersey (B1), Hall of Fame (B1), Nobel Peace Prize (B1), New York (B2), Metropolitan Correctional Centre (B2), Nasdaq (B2), Hollywood (B2), Madoff Securitied International Limited (T2), Mayfair (T2), etc.

Acronyms: N.Y. (B1), TV (B2), US (B2).

The examples above show that in both broadsheets and tabloids full name proper nouns are overwhelmingly more than acronyms in the samples. Most of those full name proper nouns are related to names of people and places which are essential to manifest the information of this event.

From the aspect of using proper nouns, contrasts of sample news reports will be shown by the following table.

Table 4. Number of proper nouns and the percentage compared with total number of words in the sample reports

\begin{tabular}{ccccc}
\hline Samples & B1 & B2 & T1 & T2 \\
\hline Number of proper nouns & 76 & 63 & 40 & 24 \\
Number of total words & 1272 & 813 & 680 & 375 \\
Percentage of proper nouns & $5.97 \%$ & $7.75 \%$ & $5.88 \%$ & $6.4 \%$ \\
\hline
\end{tabular}

Table 4 manifests that broadsheets use more proper nouns than those of tabloids, but the result is not significant.

As shown in the data collection above, broadsheets and tabloids do not present distinctive differences in using 
proper nouns. This may be attributed to the fact that the Madoff event is a political matter. The addressees need to be clear and complete to avoid any misunderstanding otherwise. If the samples are about entertainments or less serious events or issue, the result might be different. Of course, it requires statistical support.

\subsubsection{Vivid Words}

Some words improve vividness and expand the room of imagination in a news report. An American journalist Eric Sevareid said "One good word is worth a thousand pictures." Appropriate wording is very helpful in writing, especially in news writing. Using vivid words may arouse the readers' enthusiasm, and create appealing stories. This is the part for readers to appreciate the beauty and subtlety of language. However, for language learners, this part poses the greatest challenge in both reading and writing.

Writers usually use "lifeline" to express "important route", "skyrocket" to "increase sharply and suddenly", "hawk" to "hardliner", "shock wave" to "powerful influence" and "high gear" to "high efficiency". They also use "courting" to "seek friendly relations", "wedding" to "close association or union", "divorce" to "breakup of relationship" and "flirt" to "make an insincere proposition of friendly relationship".

Vivid words usually can be divided into two categories. The first category is verbs or verb phrases which can vividly and precisely describe actions or pictures of the events. For example:

He admitted his guilt for the first time in public, and apologized to his victims, dozens of whom were squeezed into the courtroom benches behind him, before being handcuffed and led away to jail to await sentencing (B1).

Madoff, 70, appeared nervous as he came face to face with several dozen of his former clients in Manhattan Federal Court (B2).

Disgraced Wall Street financier Bernie Madoff was hauled away in handcuffs today after he pleaded guilty to 11 felony charges - including securities and wire fraud - in connection with running a massive, $\$ 65$ billion Ponzi scheme (T1.)

He told the court: I wired money between the United States and the United Kingdom to make it appear as if there were actual transactions (T2).

Another category is the words which can manifest a specific state or situation, or change. For example:

But, preparing for jail, he wore no wedding ring - only the shadowy imprint remained of one he has worn for nearly 50 years (B1).

Instead, Madoff was taken last night to a holding cell the size of a walk-in cupboard to spend the night on a bunk bed at the Metropolitan Correctional Centre (B2).

The feds said that the once-revered investment fund manager admitted to his sons last year that his firm was all a big lie - a Ponzi scheme that wiped out fortunes and trust funds (T1).

Yesterday a few of his scammed investors were given a chance to speak by the judge - but shamed Madoff refused to make eye contact (T2).

From the aspect of using vivid words, contrasts of sample news reports will be shown by the following table.

Table 5. Number of vivid words and the percentage compared with total number of words in the sample reports

\begin{tabular}{ccccc}
\hline Samples & B1 & B2 & T1 & T2 \\
\hline Number of vivid words & 18 & 6 & 7 & 6 \\
Number of total words & 1272 & 813 & 680 & 375 \\
Percentage of vivid words & $1.42 \%$ & $0.74 \%$ & $1.03 \%$ & $1.6 \%$ \\
\hline
\end{tabular}

As shown in the table above, broadsheets and tabloids do not present significant difference in using vivid words. It is no surprise that the purpose of newspaper stories is to attract more readers and increase its circulation. Market share is a big concert for newspaper industry no matter what types of newspapers. Both types employ vivid words to polish their language, and make the story more appealing. For ESL learners, accumulating words like these will benefit them a lot in language acquisition. 


\section{Discussions}

The purpose of this study is to study the lexical features in broadsheets and tabloids. It compares and contrasts wording in the two types of newspapers in five lexical levels: the use of compound words, fuzzy words, numbers, proper nouns, and vivid words. Contrastive analysis has been done for the four selected English news dealing with the same subject matter. Statistics have shown that there are both similarities and differences at lexical levels between the two types of English newspapers, namely broadsheets and tabloids. Based on the review of some basic definitions of news and previous studies of lexical features of English news, the analysis is done from five lexical aspects. Generally speaking, the use of compound words do not show significant differences between the two. That is to say, compound words are preferred in both broadsheets and tabloids reports. They are the combinations of two or more simple words, but a brand new form and sometimes even new meanings are created. For writers, compound words deliver a sense of originality as well as conciseness. For readers, however, the meaning of compound words depend much on the context. Some of the words are used for the purpose of being humorous, some being ironic, and some achieving conciseness. The structures and formations of compound words are also complex. For ESL learners, grasping the patterns of compound words may help them increase their English vocabulary and skills in both reading comprehension as well as English writing.

As to fuzzy words, the total quantity of fuzzy words employed in broadsheet seems to be larger than tabloids, at least it is the case in this study. Comparatively speaking, fuzzy words rank the second to only numbers in all five types of words. It indicates that newspapers, on the one hand, need to achieve accuracy and reliability; on the other hand, fuzzy expressions help newspapers avoid possible controversy over sensitive issues, and reduce risks of potential legal liability.

Numbers are used to support the reports and are regarded as solid prove. Therefore, it is quite reasonable to draw the conclusion that broadsheets, which adopt serious stories and events, use more numbers than tabloids. However, the result turns out to be just the opposite. One sound explanation for this phenomenon is that when reading newspapers, readers do skimming and scanning more than careful readings. Numbers are very easy to recognize and spot when people scan the news. A large number of audience are more willing to know how much percentage the stock market has risen or fallen, or how many people are killed in the accident rather than the cause and effect of the event. For this purpose, using numbers to attract people's attention is much easier than using particular wording or sentence patterns. Considering the target audience, it would be quite plausible for tabloids to adopt more numbers. It is also important to notice that numbers rank the first among all five types of words. It indicates that using numbers to support the arguments or depicting facts are common policies employed in newspaper reports, because numbers are direct, concrete, and convincing.

The use of vivid words do not present much difference between broadsheets and tabloids. These words help to polish the language and improve the readability of the stories. On the other hand, how much one understands and commands these words depends much on the language levels of the readers. For ESL learners, learning to use these words in their writings will greatly improve their language skills.

\section{Limitations}

First, the subject matter concerned in this study is unitary. Lexical features could be limited by the subject matter of the news report. Wording could be managed differently in different subjects, and the frequency of words could vary. Hence, adopting various subjects of news reports in the future study is necessary. Second, data collection of samples selected are inadequate. In this paper, only four samples are selected from four newspapers. This selection could not exhibit the universal pattern of lexical features compared in the samples, and this could limit the accuracy of the result. Third, due to limitation of the length of the paper, the lexical features compared in this paper are only five. In fact, there are more than ten lexical features of English news reports. The result of this comparison could not present the whole picture of these two types of newspapers at lexical level. In the future study, comparing more lexical features of English news is necessary for the study of English news.

\section{References}

David, C., \& Davy, D. (1969). Investigating English Style. London: Longman.

Fowler, R. (1991). Language in the News: Discourse and Ideology in the Press. London: Routledge.

Fred, F. (1973). Reporting for the Print Media. Fort Worth: Harcourt Brace Jovanovich.

Hou, W.-R. (1988). Varieties of English. Shanghai: Shanghai Foreign Languages Education Press.

Hu, Z.-L. (2000). Theoretical Stylistics. Beijing: Foreign Language Teaching and Research Press.

Itule, B. D., \& Douglas, A. A. (2003). News Writing and Reporting for Today's Media. Beijing: Foreign 
Language Teaching and Research Press.

Li, X.-Z. (2001). Essence of Linguistics. Jinan: Shangdong University Press.

Newsom, D., \& Wollert, J. A. (1985). Media Writing: News for the Mass Media. California: Wadsworth, Inc.

Qin, X.-B. (1986). A Survey of Stylistics. Changsha: Hunan Education Press.

Wang, Z.-L, \& Ding, W.-D. (1985). Introduction to English Stylistics. Beijing: Foreign Language Teaching and Research Press.

Zadeh, L. A. (1965). Fuzzy Sets. Information and Control, 8(3), 338-353.

Zeng, Z.-X. (2006). A Contrastive Study of Styles between Quality Newspaper and Popular Newspaper. Bejing: Capital Normal University.

Zhang, J. (2007). English in News Publications. Shanghai Foreign Language Education Press.

Zhang, J. (2007). Studies in English Newspaper and Magazines. Shanghai: Shanghai Foreign Language Education Press.

\section{Copyrights}

Copyright for this article is retained by the author(s), with first publication rights granted to the journal.

This is an open-access article distributed under the terms and conditions of the Creative Commons Attribution license (http://creativecommons.org/licenses/by/3.0/). 